\title{
The influence of calcium-phosphate metabolism abnormalities on the quality of life in patients with hemodynamically significant mitral regurgitation
}

\author{
Olga Mozenska ${ }^{1,2^{*}}$, Jacek Bil ${ }^{3}$ D, Agnieszka Segiet ${ }^{1}$ and Dariusz A. Kosior ${ }^{4}$
}

\begin{abstract}
Background: In recent years, studies have indicated that vitamin $\mathrm{D}\left[25(\mathrm{OH}) \mathrm{D}_{3}\right]$ and other calcium-phosphate (Ca-P) metabolism parameters and their disturbances might be potential new factors that may influence health-related quality of life (HRQoL). The aim of our study was to assess the extent of Ca-P metabolism abnormalities in patients with significant mitral regurgitation (MR) and their effect on patients' HRQOL.

Methods: We included 99 patients with significant MR (median age, 75 years [Q1-Q3, 66.0-81.5], 35.4\% females). Hemodynamically significant MR was assessed using transthoracic echocardiography (vena contracta $>3 \mathrm{~mm}$, effective orifice area $>0.2 \mathrm{~cm}^{2}$, and MR volume $>30 \mathrm{~mL} / \mathrm{s}$ ). HRQoL was evaluated using a cardiac-specific (MacNew) tool.

Results: A significant negative correlation between parathormone (PTH) levels and HRQoL was demonstrated $(r=$ $-0.242,-0.243$, and $-0.255 ; p=0.018,0.018$, and 0.013 for Global Scores, and physical and social domains, respectively). Additionally, we confirmed that patients with higher NT-proBNP levels, NYHA heart failure (HF) class, and larger left ventricles had poorer HRQoL. Moreover, patients with poorer HRQoL walked a shorter distance in a 6-min walking test.

Conclusions: To the best of our knowledge, this report is the first to show that Ca-P abnormalities resulted in significantly worse HRQoL, especially in the physical domain, in a population of patients with hemodynamically significant MR.
\end{abstract}

Keywords: Vitamin D, Hypocalcemia, Valvular heart disease, MacNew, parathormone, Quality of life, Health-related quality of life

\section{Background}

Valvular heart disease, after coronary artery disease and hypertension, is the third most common cause of heart failure (HF). In Europe, mitral regurgitation (MR) is the second most frequently acquired valve disease in adults [1]. As the population ages and life expectancy increases, living a healthy and longer quality life is becoming more important for

\footnotetext{
* Correspondence: olgamozenska@gmail.com

'Department of Cardiology and Hypertension, Central Clinical Hospital of the Ministry of the Interior and Administration, Woloska Street 137, 02-507 Warsaw, Poland

${ }^{2}$ Department of Internal Medicine, Hypertension and Vascular Diseases, Warsaw Medical University, Banacha Street 1a, 02-097 Warsaw, Poland Full list of author information is available at the end of the article
}

communities and individuals [2-4]. Along with that comes a wish to address ways for improving health-related quality of life (HRQoL). In patients with MR, several factors have been associated with HRQoL, such as impaired left ventricular function or end-systolic diameter of the left ventricle $\geq 45$ mm [5-7]. One should also consider HRQoL depending on the repair method $[8,9]$. Moreover, the psychoemotional status has proven to influence HRQoL [10-12]. In recent years, studies have indicated that vitamin $\mathrm{D}\left[25(\mathrm{OH}) \mathrm{D}_{3}\right]$ and other calcium-phosphate (Ca-P) metabolism parameters and their disturbances might be potential new factors that may influence HRQoL. Considering the frequencies of Ca-P metabolism abnormalities and $\mathrm{MR}$ in general and in the

(c) The Author(s). 2019 Open Access This article is distributed under the terms of the Creative Commons Attribution 4.0 International License (http://creativecommons.org/licenses/by/4.0/), which permits unrestricted use, distribution, and reproduction in any medium, provided you give appropriate credit to the original author(s) and the source, provide a link to the Creative Commons license, and indicate if changes were made. The Creative Commons Public Domain Dedication waiver (http://creativecommons.org/publicdomain/zero/1.0/) applies to the data made available in this article, unless otherwise stated. 
cardiovascular population, we aimed to assess the influence of Ca-P metabolism disturbances on HRQoL in this type of population.

\section{Methods}

\section{Study population}

The study population consisted of 99 patients hospitalized in our Cardiology Department between July 1, 2013 and September 30, 2013 [13]. The patients were hospitalized on an elective basis and in an emergency. Summer months were typically chosen to ensure feasible and constant exposure to sunlight. The study inclusion criteria were age over 18 years and significant MR assessed using transthoracic echocardiography (vena contracta $>3 \mathrm{~mm}$, effective orifice area $>0.2 \mathrm{~cm}^{2}$, and MR volume $>30 \mathrm{~mL} /$ $\mathrm{s})$. The exclusion criteria were lack of written informed consent, prior medical history of invasive MV treatment (surgical or percutaneous MV repair and surgical MV replacement), MV stenosis of any kind, chronic kidney disease requiring dialysis, prior medical history of thyroid or parathyroid gland disorders (including status post thyroidectomy or post parathyroidectomy), clinical situation requiring temporary (at least 2 weeks) or permanent immobilization 6 months before being included in our study, and routine use of $\mathrm{Ca}$ or vitamin $\mathrm{D}$ supplements. At the time of hospital admission, we performed physical examination, obtained anthropometric measurements, and collected detailed prior medical history. We concentrated on valvular heart disease, Ca-P metabolism, vitamin $\mathrm{D}$ deficiency, dietary regimens, physical activity, and vitamin supplements. The course of each hospitalization was standard and adequate to determine symptoms, clinical status, initial diagnosis, and comorbidities.

\section{Biochemical parameters}

Blood specimens were obtained in a standardized fashion in the morning, after at least $12 \mathrm{~h}$ of fasting and $30 \mathrm{~min}$ of resting in a supine position in a quiet, environmentally controlled room. Fasting morning urinary samples and 24-h urinary samples were collected. The serum PTH levels were determined using Elecsys PTH (1-84) test (Cobas ${ }^{\oplus}$, Roche Diagnostics $\mathrm{GmbH}$, Germany). Vitamin D $\left(25(\mathrm{OH}) \mathrm{D}_{3}\right)$ levels were measured using the LIAISON test (DiaSorin Inc., USA). To calculate $[\mathrm{Ca}]_{\mathrm{alb}}$ and $\left[\mathrm{Ca}^{2+}\right]_{\mathrm{pH}}$, we used the standard formulas $[14,15]$.

The laboratory calibration references for $\mathrm{Ca}-\mathrm{P}$ metabolism parameters were as follows: $[\mathrm{Ca}]_{\mathrm{alb}}$ (serum), 2.19$2.54 \mathrm{mmol} / \mathrm{L} ;\left[\mathrm{Ca}^{2+}\right]_{\mathrm{pH}}$ (serum), $1.13-1.32 \mathrm{mmol} / \mathrm{L}$; daily urinary $\mathrm{Ca}$ secretion, $2.5-6.25 \mathrm{mmol} / 24 \mathrm{~h}$ (females) and $3.75-7.5 \mathrm{mmol} / 24 \mathrm{~h}$ (males); phosphates (serum), 0.9$1.5 \mathrm{mmol} / \mathrm{L}$; phosphates (urine), 40-136 mg/dL; daily urinary phosphate secretion, $0.4-1.3 \mathrm{~g} / 24 \mathrm{~h}$; $\mathrm{PTH}$ (serum), $10-65 \mathrm{pg} / \mathrm{mL}$; and $25(\mathrm{OH}) \mathrm{D}_{3}, 30-80 \mathrm{ng} / \mathrm{mL}$.

\section{Echocardiographic parameters}

A comprehensive, standard, two-dimensional Doppler echocardiography examination was performed using a commercially available diagnostic ultrasound system (iE 33, Philips Medical System, Best, The Netherlands). All the measurements were obtained by an experienced cardiologist, in accordance with the guidelines of the European Association of Cardiovascular Imaging [16, 17].

\section{Quality of life assessment}

HRQoL was assessed using a disease-specific instrument (MacNew) [18-20]. The MacNew questionnaire is a self-administered HRQoL assessment tool developed for patients with myocardial infarction, $\mathrm{HF}$, and angina pectoris. It consists of 27 items evaluated by patients using a 7-point Likert scale (little or no symptoms, 7; severe symptoms, 1). A Global Score is calculated as the average score of three domains (social, emotional, and physical). Permission to use was obtained.

\section{Research ethics and patient consent}

The study was conducted in accordance with the World Medical Declaration of Helsinki. All study subjects provided their written, informed consent for participating in the study. The Institutional Review Board approved the study protocol (approval number 63/2013, issued July 1, 2013).

\section{Statistical analysis}

The Shapiro-Wilk test of normality was used to assess the distribution of continuous variables, and continuous variables were reported as the mean \pm standard deviation values for normally distributed variables. Median [first quartile-third quartile] was reported for the variables deviating from normal distribution. Categorical variables were reported as frequencies and percentages. To compare continuous variables, Student's $t$-test was used for normally distributed variables, and MannWhitney test was used for variables deviating from normal distribution. Categorical variables were compared using Fisher's exact test. The influence of selected clinical, echocardiographic, and biochemical variables on HRQoL was assessed using univariable and multivariable logistic regression models. The significance level was set at 0.05 . Statistical analysis was performed using R 3.1.2 statistical package ( $\mathrm{R}$ Core Team (2014). R: A language and environment for statistical computing. R Foundation for Statistical Computing, Vienna, Austria. Available at http://www.R-project.org/).

\section{Results}

Baseline characteristics

We screened 376 potentially eligible patients, of whom 257 did not meet the study criteria, and 20 patients did not sign the informed consent form. Ultimately, we enrolled 99 patients with a median age of 75 years (IQR, 66.0-81.5). All study subjects had HF (NYHA I, 36.4\%; 
NYHA II, 34.3\%; NYHA III, 11.1\%; and NYHA IV, $18.2 \%) ; 64.6 \%$ had hypertension, and $46.5 \%$ had chronic kidney disease. The clinical characteristics of study patients and detailed echocardiographic and biochemical parameters are presented in Tables 1 and 2. The median serum level of calcium corrected by albumin was 3.22 $\mathrm{mmol} / \mathrm{L}$ (IQR, 3.14-3.27), and the mean serum phosphate level was $3.51 \pm 0.62 \mathrm{mmol} / \mathrm{L}$. The median serum PTH level, which was $63.10 \mathrm{pg} / \mathrm{mL}$ (IQR, 40.95-88.55), was abnormally elevated in $48.42 \%$ of the study population. In $92.71 \%$ of the study cohort, we acknowledged $25(\mathrm{OH}) \mathrm{D}_{3}$ deficiency. Detailed Ca-P metabolism components and frequency of their disturbances are shown in Table 3.

Influence of ca-P parameters abnormalities on HRQoL of patients with hemodynamically significant MR

We observed a significant negative influence of the increase in PTH levels on the Global Score $(\mathrm{r}=-0.242 ; p=$ $0.018)$ and HRQoL in physical and social domains $\left(r_{1}=-\right.$ $0.243, \mathrm{p}_{1}=0.018 ; \mathrm{r}_{2}=-0.255 ; \mathrm{p}_{2}=0.013$ for physical and social domains, respectively). To determine the exact influence of $\mathrm{Ca}-\mathrm{P}$ metabolism parameters on individual MacNew domains, we compared HRQoL scores reported by patients in two subgroups with and without disturbed $\mathrm{Ca}-\mathrm{P}$ metabolism parameters. In the subgroup with elevated PTH levels, the mean Global Score was significantly lower than that in the subgroup with PTH levels within the normal range $(4.05 \pm 1.29,4.34 \pm 1.26$, and $3.76 \pm 1.39$ for the entire study population, subgroup with normal PTH levels and subgroup with elevated PTH levels, respectively; $p=0.031$ ). Also, the median scores in the physical and social domains were significantly lower in the subgroup with elevated PTH levels (physical domain: 3.58 [2.65-4.83], 3.69 [2.69-4.83], and 3.15 [2.73-4.96] for the entire study population, subgroup with normal and subgroup with elevated PTH levels, respectively; $p=0.027$; social domain: 3.92 [3.00-5.23], 4.46 [3.31-5.54], and 3.50 [2.79-4.73] for the entire study population, subgroup with normal and subgroup with elevated PTH levels, respectively; $p=0.019$ ). Regarding other evaluated Ca-P metabolism parameters, no

Table 1 Study population characteristics

\begin{tabular}{|c|c|}
\hline Parameter & Study group $\mathrm{n}(\%) /$ mean $\pm \mathrm{SD} /$ median $[\mathrm{IQR}]$ \\
\hline Total number of patients: & $N=99$ \\
\hline Age (years) & $75.0[66.0-81.5]$ \\
\hline Female & $35(35.4)$ \\
\hline Weight (kg) & $80.0[67.0-87.8]$ \\
\hline Body mass index $\left(\mathrm{kg} / \mathrm{m}^{2}\right)$ & $26.5[24.2-30.2]$ \\
\hline Body surface area $\left(\mathrm{m}^{2}\right)$ & $1.89 \pm 0.25$ \\
\hline \multicolumn{2}{|l|}{ Comorbidities: } \\
\hline $\mathrm{HF}$ with preserved ejection fraction & $32(32.3)$ \\
\hline HF with reduced ejection fraction & $44(44.4)$ \\
\hline Right ventricular HF & $25(25.3)$ \\
\hline Dilated cardiomyopathy & $36(36.4)$ \\
\hline Arterial hypertension & $64(64.6)$ \\
\hline Diabetes & $32(32.3)$ \\
\hline Chronic kidney disease & $46(46.5)$ \\
\hline stage I - II & $60(60.6)$ \\
\hline stage III - IV & $39(39.4)$ \\
\hline Atrial fibrillation & $39(63.9)$ \\
\hline Osteoarthritis & $24(24.2)$ \\
\hline Distance in 6-min walking test $(\mathrm{m})$ : & $150.0[40.0-440.0]$ \\
\hline \multicolumn{2}{|l|}{ Pharmacotherapy: } \\
\hline Beta-blockers & $85(87.6)$ \\
\hline ACEi & $78(80.4)$ \\
\hline ARBs & $11(11.3)$ \\
\hline Ca channel antagonists & $20(20.6)$ \\
\hline Diuretics & $76(78.4)$ \\
\hline Mineralocorticoid receptor antagonists & $35(36.1)$ \\
\hline
\end{tabular}

ACEi, angiotensin converting enzyme inhibitors; ARBs, angiotensin receptor blockers; $\mathrm{HF}$ - heart failure 
Table 2 Baseline echocardiographic and laboratory findings

\begin{tabular}{|c|c|}
\hline Parameter & Study group mean \pm SD / median [IQR] \\
\hline \multicolumn{2}{|l|}{ Echocardiography: } \\
\hline LVEF (\%) & $50.0[29.0-62.0]$ \\
\hline LVEDd (mm) & $56.0[49.5-65.0]$ \\
\hline $\operatorname{LVED}_{\text {vol }}(\mathrm{mL})$ & $111.5[79.0-182.3]$ \\
\hline LVED $_{\text {vol }} / B S A$ & $58.4[43.2-91.4]$ \\
\hline IVSDd (mm) & $10.0[10.0-11.8]$ \\
\hline PWDd (mm) & $10.0[9.0-11.0]$ \\
\hline$L A_{\text {vol. }}(\mathrm{mL})$ & $100.0[71.3-126.0]$ \\
\hline $\mathrm{LA}_{\mathrm{vol}} / \mathrm{BSA}$ & $53.0[38.2-65.5]$ \\
\hline $\operatorname{RVSP}(\mathrm{mmHg})$ & $43.0[39.0-53.5]$ \\
\hline TAPSE (mm) & $22.0 \pm 6.8$ \\
\hline Mitral valve annulus (mm) & $37.4 \pm 6.4$ \\
\hline Vena contracta $(\mathrm{mm})$ & $6.0[5.0-7.0]$ \\
\hline PISA radius (mm) & $6.0[5.0-7.0]$ \\
\hline Mitral regurgitation volume (ml/beat) & $23.0[17.0-31.0]$ \\
\hline ERO $\left(\mathrm{cm}^{2}\right)$ & $0.15[0.10-0.22]$ \\
\hline \multicolumn{2}{|l|}{ Laboratory tests: } \\
\hline creatinine (mmol/L) & $1.03[0.83-1.22]$ \\
\hline $\operatorname{eGFR}\left(\mathrm{mL} / \mathrm{min} / 1.73 \mathrm{~m}^{2}\right)$ & $67.11 \pm 24.09$ \\
\hline albumins (g/L) & $4.00[3.72-4.22]$ \\
\hline total proteins $(\mathrm{g} / \mathrm{L})$ & $6.52 \pm 0.69$ \\
\hline C-reactive protein:(mg/L) & $2.80[1.10-8.47]$ \\
\hline NT-proBNP (pg/ml) & $1815.0[583.5-3483.3]$ \\
\hline
\end{tabular}

BSA, body surface area; $L V E F$, left ventricular ejection fraction; $L V D$ d, left ventricular diastolic diameter; $L V E D_{\text {vol, }}$ left ventricular end-diastolic volume; IVSDd, intraventricular septum diastolic diameter; PWDd, posterior wall diastolic diameter; $L A_{\text {vol, }}$ left atrial volume; RVSP, right ventricular systolic pressure; TAPSE, tricuspid annular plane systolic excursion; PISA, proximal isovolumetric surface area; ERO, effective regurgitant orifice area

significant influence on HRQoL was observed. The results of Ca-P metabolism parameters and their influence on HRQoL are presented in Tables 4 and 5.

\section{Factors predicting HRQoL in patients with} hemodynamically significant MR

To determine the influence of patients' age and gender on HRQoL in the studied population, we used dual linear regression. Based on the obtained results, we identified a significant influence of gender on MacNew emotional domain. Higher scores were observed in men $(r=0.730 ; 95 \%$ CI, 0.160-1.300; $p=0.014$ ). We did not find significant relationships between age, gender, and other domains.

To ascertain the influence of clinical parameters on HRQoL we built a series of linear regression models considering age, gender, and chosen clinical parameter. We found that patients with higher NYHA HF class reported significantly poorer Global Scores $(\mathrm{r}=-1.003, p=0.001 ; \mathrm{r}=-$

Table 3 Calcium-phosphate metabolism components and their incidence frequency in the studied population

\begin{tabular}{|c|c|c|c|}
\hline Parameter & Study group mean \pm SD / median [IQR] & Frequency of deficiency [\%] & Frequency of excess [\%] \\
\hline$[\mathrm{Ca}]_{\mathrm{alb} .}(\mathrm{mmol} / \mathrm{L})($ serum$)$ & $3.22[3.14-3.27]$ & 0 & 100 \\
\hline$\left[\mathrm{Ca}^{2+}\right]_{\mathrm{pH}}(\mathrm{mmol} / \mathrm{L})$ (serum) & $1.05 \pm 0.08$ & 84.3 & 0 \\
\hline Calcium 24-h urinary excretion (mmoL/24 h) & $2.25[1.28-2.92]$ & 56.6 & 4.0 \\
\hline Phosphates (serum) (mmol/L) & $3.51 \pm 0.62$ & 0 & 100 \\
\hline Phosphates (urine) (mg/dL) & $30.00[18.15-37.65]$ & 76.0 & 2.7 \\
\hline Phosphates 24-h urinary excretion (g/24 h) & $0.47[0.32-0.75]$ & 36.0 & 2.7 \\
\hline PTH (serum) (pg/mL) & $63.10[40.95-88.55]$ & 0 & 48.4 \\
\hline $25(\mathrm{OH}) \mathrm{D}_{3}(\mathrm{ng} / \mathrm{mL})$ & $14.80[9.93-20.12]$ & 92.7 & 0 \\
\hline
\end{tabular}

Ca, calcium; PTH, parathormone 
Table 4 Calcium-phosphates metabolism parameters and their influence on health-related quality of life in patients with significant mitral regurgitation

\begin{tabular}{|c|c|c|c|}
\hline Calcium-phosphate metabolism parameter & MacNew domain & Spearman's rank correlation coefficient & $p$-value \\
\hline \multirow[t]{4}{*}[\mathrm{Ca}]{$_{\text {cor.albumins }}(\mathrm{mmol} / \mathrm{L})$ (serum) } & Global Score & -0.043 & NS \\
\hline & physical & -0.019 & NS \\
\hline & emotional & -0.089 & NS \\
\hline & social & -0.017 & NS \\
\hline \multirow[t]{4}{*}[\mathrm{Ca}^{2+}]{$_{\mathrm{cor} . \mathrm{pH}}(\mathrm{mmol} / \mathrm{L})($ serum$)$} & Global Score & 0.062 & NS \\
\hline & physical & 0.081 & NS \\
\hline & emotional & 0.044 & NS \\
\hline & social & 0.063 & NS \\
\hline \multirow[t]{4}{*}{ Calcium 24-h urinary excretion ( $\mathrm{mmoL} / 24 \mathrm{~h}$ ) } & Global Score & -0.030 & NS \\
\hline & physical & -0.056 & NS \\
\hline & emotional & -0.003 & NS \\
\hline & social & -0.012 & NS \\
\hline \multirow[t]{4}{*}{ Phosphates (urine) (mg/dL) } & Global Score & 0.051 & NS \\
\hline & physical & 0.074 & NS \\
\hline & emotional & 0.038 & NS \\
\hline & social & -0.006 & NS \\
\hline \multirow[t]{4}{*}{ Phosphates 24-h urinary excretion (g/24 h) } & Global Score & 0.097 & NS \\
\hline & physical & 0.128 & NS \\
\hline & emotional & 0.098 & NS \\
\hline & social & 0.063 & NS \\
\hline \multirow[t]{4}{*}{ PTH (serum) (pg/mL) } & Global Score & -0.242 & 0.018 \\
\hline & physical & -0.243 & 0.018 \\
\hline & emotional & -0.176 & NS \\
\hline & social & -0.255 & 0.013 \\
\hline \multirow[t]{4}{*}{$25(\mathrm{OH}) \mathrm{D}_{3}(\mathrm{ng} / \mathrm{mL})$} & Global Score & 0.157 & NS \\
\hline & physical & 0.189 & 0.066 \\
\hline & emotional & 0.122 & NS \\
\hline & social & 0.161 & NS \\
\hline
\end{tabular}

Ca, calcium; PTH, parathormone

1.018, $p=0.012 ; \mathrm{r}=-1.558, p<0.001$, for NYHA class II, III, and IV, respectively) and had poorer HRQoL in all other three domains $(\mathrm{r}=-1.186, p<0.001 ; \mathrm{r}=-1.092, p=0.016 ; \mathrm{r}$ $=-1.687, p<0.001 ; \mathrm{r}=-0.833, p=0.006 ; \mathrm{r}=-1.483, p<$ $0.001 ; \mathrm{r}=-1.070, \mathrm{p}=0.001 ; \mathrm{r}=-1.24, p=0.007 ; \mathrm{r}=-1.763$, $p<0.001$ for NYHA class II, III, and IV, respectively, for physical, emotional, and social domains, respectively). Further analysis revealed that lower Global Scores and poorer HRQoL in all three domains resulted in shorter distance walked by patients during a 6 min walking test $\left(r_{1}=0.004\right.$, $p_{1}<0.001 ; \mathrm{r}_{2}=0.004, p_{2}<0.001 ; \mathrm{r}_{3}=0.004, p_{3}<0.001 ; \mathrm{r}_{4}=$ $0.004, \mathrm{p}_{4}<0.001$ for Global Scores, physical, emotional, and social domains, respectively) (Fig. 1).

To determine the influence of echocardiographic and biochemical parameters on HRQoL, we again built a series of linear regression models considering age, gender, and chosen echocardiographic or biochemical parameter. We concluded that patients with larger left ventricular systolic and diastolic volumes had lower Global Scores $\left(r_{1}=-0.006,95 \%\right.$ CI, 0.010 to $0.002, \mathrm{p}_{1}=0.008 ; 95 \% \mathrm{CI},-0.029$ to $-0.003, \mathrm{r}_{2}=-$ 0.011, $\mathrm{p}_{2}=0.009$ for $\mathrm{LVES}_{\mathrm{vol}}$. and $\mathrm{LVES}_{\mathrm{vol}}$. indexed for $\mathrm{BSA}$, respectively, and $\mathrm{r}_{1}=-0.004,95 \% \mathrm{CI}$, 0.008 to $-0.000, \mathrm{p}_{1}=0.045 ; \mathrm{r}_{2}=-0.008,95 \% \mathrm{CI},-$ 0.015 to $-0.000, \mathrm{p}_{2}=0.049$ for LVED $_{\text {vol. }}$ and LVEDvol. indexed for BSA, respectively). We observed similar relationships for physical and social domains. Moreover, we showed that patients with higher NT-proBNP levels had poorer HRQoL in the physical and social domains $\left(r_{1}=0.000,95 \%\right.$ CI, $-0,000$ to $-0,000, p_{1}=0.036 ; r_{2}=0.000,95 \% \mathrm{CI},-0.000$ to $\left.-0.000, p_{2}=0.044\right)$. 
Table 5 Calcium-phosphates metabolism parameters and their disturbances and their influence on health-related quality of life in patients with significant mitral regurgitation

\begin{tabular}{|c|c|c|c|c|c|}
\hline $\begin{array}{l}\text { Calcium-phosphates metabolism } \\
\text { parameter }\end{array}$ & MacNew domain & $\begin{array}{l}\text { Study population mean } \\
\pm \mathrm{SD} / \text { median [Q1-Q3] }\end{array}$ & $\begin{array}{l}\text { No disturbance mean } \\
\pm \mathrm{SD} / \text { median [Q1-Q3] }\end{array}$ & $\begin{array}{l}\text { Disturbance present mean } \\
\pm \mathrm{SD} / \text { median [Q1-Q3] }\end{array}$ & $p$-value \\
\hline \multirow[t]{8}{*}{$\begin{array}{l}\mathrm{Ca}]_{\text {koralbumins }}:(\mathrm{mmol} / \mathrm{L}) \\
\text { (serum) }\end{array}$} & $\begin{array}{l}\text { Global } \\
\text { Score }\end{array}$ & $4.05 \pm 1.29$ & $4.08 \pm 1.41$ & $4.05 \pm 1.26$ & NS \\
\hline & physical & $3.58[2.65-4.83]$ & $3.79[2.69-4.80]$ & $3.69[2.69-4.76]$ & NS \\
\hline & emotional & $4.18 \pm 1.36$ & $4.27 \pm 1.55$ & $4.17 \pm 1.35$ & NS \\
\hline & social & $3.92[3.00-5.23]$ & $4.08[2.75-5.38]$ & $3.92[3.08-5.08]$ & NS \\
\hline & $\begin{array}{l}\text { Global } \\
\text { Score }\end{array}$ & $4.05 \pm 1.29$ & $3.98 \pm 1.25$ & $3.88 \pm 1.30$ & NS \\
\hline & physical & $3.58[2.65-4.83]$ & $3.15[2.62-4.69]$ & $3.69[2.52-4.65]$ & NS \\
\hline & emotional & $4.18 \pm 1.36$ & $4.10 \pm 1.38$ & $4.04 \pm 1.44$ & NS \\
\hline & social & $4.13 \pm 1.43$ & $4.07 \pm 1.41$ & $3.96 \pm 1.41$ & NS \\
\hline \multirow[t]{4}{*}{$\begin{array}{l}\text { Calcium 24-h urinary excretion: } \\
\text { (mmol/24 h) }\end{array}$} & $\begin{array}{l}\text { Global } \\
\text { Score }\end{array}$ & $4.05 \pm 1.29$ & $3.79 \pm 1.42$ & $3.98 \pm 1.24$ & NS \\
\hline & physical & $3.58[2.65-4.83]$ & $3.15[2.63-4.00]$ & $3.69[2.58-4.83]$ & NS \\
\hline & emotional & $4.18 \pm 1.36$ & $3.92 \pm 1.69$ & $4.14 \pm 1.31$ & NS \\
\hline & social & $4.13 \pm 1.43$ & $3.74 \pm 1.50$ & $4.09 \pm 1.39$ & NS \\
\hline \multirow[t]{4}{*}{ Phosphates (urine): (mg/dL) } & $\begin{array}{l}\text { Global } \\
\text { Score }\end{array}$ & $4.05 \pm 1.29$ & $4.06 \pm 1.20$ & $3.70 \pm 1.40$ & NS \\
\hline & physical & $3.58[2.65-4.83]$ & $3.64[2.80-4.69]$ & $2.83[2.40-4.72]$ & NS \\
\hline & emotional & $4.18 \pm 1.36$ & $4.23 \pm 1.32$ & $3.83 \pm 1.53$ & NS \\
\hline & social & $4.13 \pm 1.43$ & $4.13 \pm 1.34$ & $3.79 \pm 1.53$ & NS \\
\hline \multirow[t]{4}{*}{$\begin{array}{l}\text { Phosphates } 24-h \text { urinary } \\
\text { excretion: (g/24h) }\end{array}$} & $\begin{array}{l}\text { Global } \\
\text { Score }\end{array}$ & $4.05 \pm 1.29$ & $4.34 \pm 1.26$ & $3.76 \pm 1.30$ & 0.031 \\
\hline & physical & 3.58 [2.65-4.83] & $4.08[2.92-5.00]$ & 3.12 [2.58-4.42] & 0.027 \\
\hline & emotional & $4.18 \pm 1.36$ & $4.41 \pm 1.26$ & $3.93 \pm 1.48$ & 0.093 \\
\hline & social & $3.92[3.00-5.23]$ & $4.46[3.31-5.54]$ & 3.50 [2.79-4.73] & 0.019 \\
\hline \multirow[t]{4}{*}{ PTH (serum): (pg/mL) } & $\begin{array}{l}\text { Global } \\
\text { Score }\end{array}$ & $4.05 \pm 1.29$ & $4.15 \pm 1.21$ & $4.06 \pm 1.32$ & NS \\
\hline & physical & 3.58 [2.65-4.83] & 3.15 [2.73-4.96] & 3.69 [2.69-4.83] & NS \\
\hline & emotional & $4.18 \pm 1.36$ & $4.36 \pm 0.96$ & $4.17 \pm 1.41$ & NS \\
\hline & social & $3.92[3.00-5.23]$ & $3.31[3.12-5.50]$ & $3.92[3.00-5.31]$ & NS \\
\hline
\end{tabular}

Ca, calcium; PTH, parathormone

\section{Discussion}

To the best of our knowledge, our study is the first to assess the influence of selected Ca-P metabolism parameters on HRQoL in patients with significant MR. We also believe that it is the first study to identify factors determining HRQoL in this patient population.

The published data regarding HRQoL in patients with MR are derived from surgical cohorts of patients undergoing MV repair or replacement. In the analyzed papers, the authors indicated a significant influence of MR presence on HRQoL. They also found prominent HRQoL improvement in case of invasive treatment, despite the chosen surgical technique [5-12].

Due to the lack of published data to compare our results, we refer to two papers that discuss HRQoL in the context of Ca-P metabolism disturbances [21, 22]. One should keep in mind that in the cited papers, the authors presented different patient cohorts, and they used different HRQoL questionnaires. Nevertheless, in the paper by Siilin et al., the authors reported that premenopausal aged women with diagnosed $\mathrm{Ca}$ disturbances had poorer HRQoL in all assessed domains [21]. In the second article, the researchers studied the relationship between HRQoL and the frequency of hospitalizations and the markers of bone metabolism in patients with chronic kidney disease. They proved the presence of a correlation between poorer HRQoL and lower Ca levels as well as higher PTH levels [22]. In addition to presenting their own results, the authors directed attention to earlier studies that suggested a relationship between poorer $\mathrm{HRQOL}$ and $\mathrm{Ca}-\mathrm{P}$ metabolism disturbances in patients who received dialysis [22]. The reported outcomes corresponded well with our results. In our cohort, poorer 

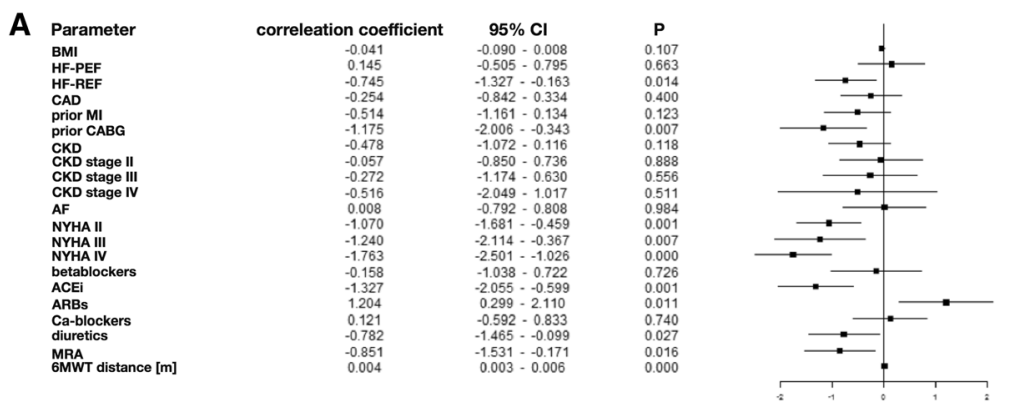

B

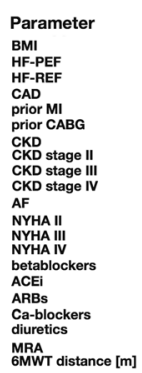

correleation coefficient
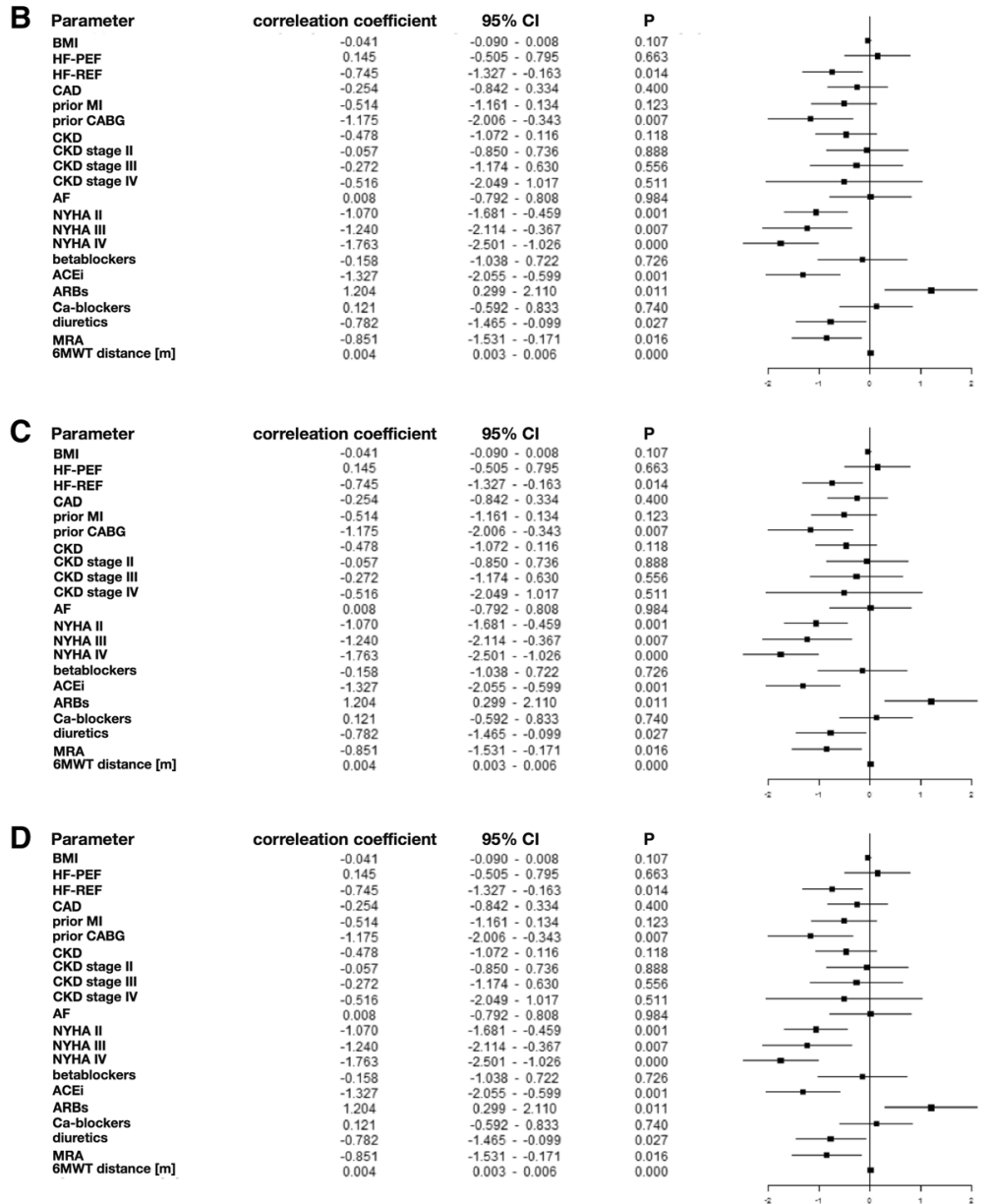

Fig. 1 The influence of clinical parameters on HRQoL. a Global score, (b) physical domain, (c) emotional domain, (D) social domain. BMI - body mass index, HF-PEF - heart failure with preserved ejection fraction; HF-REF - heart failure with reduced ejection fraction; CAD - coronary artery disease, MI - myocardial infarction; CABG - coronary artery bypass graft; CKD - chronic kidney disease; AF - atrial fibrillation; ACEi, angiotensin converting enzyme inhibitors; ARBs, angiotensin receptor blockers, MRA - mineralocorticoid receptor antagonist; 6MWT - 6-min walking test

HRQoL, as assessed by Global Scores and scores in the physical and social domains, correlated significantly with higher PTH. Additionally, we showed that in the group of patients with elevated PTH levels, the mean Global Scores were significantly lower than those in the group with $\mathrm{PTH}$ levels within the normal range. Also, the median scores in the physical and social domains were significantly lower in the subgroup with elevated PTH levels. Furthermore, in the study population, the lower the vitamin $\mathrm{D}$ level, the poorer HRQoL was reported by patients in the physical domain.

As mentioned previously, there are no publications in the literature that would identify, in the context of Ca-P metabolism disturbances, factors determining HRQoL in patients with significant MR. To gain a better understanding of the significance of HRQoL impairment in our cohort, we related this impairment to patients suffering from HF because all the patients in our study had 
this condition diagnosed. In patients with HF, the main clinical symptoms that reduce activities of daily living and contribute to exercise intolerance are dyspnea, tiredness, and fatigue. HRQoL in patients with HF may be worsened by psychological problems, physical symptoms, social limitations, and adverse treatment effects. The increasing severity of HF may lead patients to realize their own mortality, which can result in depression, sleep disturbances, and anxiety [23, 24]. The results reported by Dunderdale et al. and Berry et al. are consistent with our outcomes. We found that patients with higher NYHA HF class reported significantly poorer Global Scores and had poorer HRQoL in all other three domains. Moreover, we showed that patients with higher NT-proBNP levels had poorer HRQoL in the physical and social domains. We found corresponding results regarding echocardiography. Patients with larger left ventricular systolic and diastolic volumes had lower Global Scores. We observed similar relationships for the physical and social domains. Further analysis revealed that lower Global Scores and poorer HRQoL in all three domains resulted in shorter distance walked by patients during a 6-min walking test.

\section{Study limitations}

There are several limitations in the present study. First, the cohort size was rather small, which resulted in only 38 patients with severe MR. Second, we obtained Ca-P metabolism parameters only once during the study period. We were unable to determine several parameters, e.g., different vitamin D metabolites. Having those results would allow for a more detailed data analysis. As an additional limitation, we see the lack of long-term follow-up, including the follow-up after introducing $\mathrm{Ca}$ and vitamin $\mathrm{D}$ supplementation. Furthermore, the fact that all patients had HF might have been significant; however, more than a third of them were nearly asymptomatic. Another limitation is the lack of published data with which to compare our results, especially with respect to HRQoL.

\section{Conclusions}

To the best of our knowledge, our report is the first to show that $\mathrm{Ca}-\mathrm{P}$ abnormalities resulted in significantly worse HRQoL, especially in the physical domain, in a population of patients with hemodynamically significant MR.

\section{Abbreviations}

HF: Heart failure; HRQoL: Health-related quality of life; IQR: Interquartile range; MR: Mitral regurgitation; MV: Mitral valve; PTH: Parathormone

Acknowledgements

Not applicable.

Funding

No funding.

\section{Availability of data and materials}

The datasets used and/or analyzed during the current study are available from the corresponding author on reasonable request.

\section{Authors' contributions}

OM - designed the study, gathered data, analyzed data, prepared the paper, JB - analyzed data, prepared the paper, AS - analyzed data, prepared the paper, DK - analyzed data, prepared the paper. All authors read and approved the manuscript.

\section{Ethics approval and consent to participate}

All procedures performed in studies involving human participants were in accordance with the ethical standards of the institutional and/or national research committee and with the 1964 Helsinki declaration and its later amendments or comparable ethical standards. Institutional Review Board approved the study protocol (Ethics and Supervision Commission for research on humans and animals at Central Clinical Hospital of the Ministry of Interior and Administration in Warsaw; approval number 63/2013 issued July 1 , 2013). Written informed consent was obtained from all individual participants included in the study.

Consent for publication

Not applicable.

\section{Competing interests}

The authors declare that they have no competing interests.

\section{Publisher's Note}

Springer Nature remains neutral with regard to jurisdictional claims in published maps and institutional affiliations.

\section{Author details}

${ }^{1}$ Department of Cardiology and Hypertension, Central Clinical Hospital of the Ministry of the Interior and Administration, Woloska Street 137, 02-507 Warsaw, Poland. ${ }^{2}$ Department of Internal Medicine, Hypertension and Vascular Diseases, Warsaw Medical University, Banacha Street 1a, 02-097 Warsaw, Poland. ${ }^{3}$ Department of Invasive Cardiology, Centre of Postgraduate Medical Education, Central Clinical Hospital of the Ministry of the Interior and Administration, Woloska Street 137, 02-507 Warsaw, Poland. ${ }^{4}$ Department of Applied Physiology, Mossakowski Medical Research Centre, Polish Academy of Sciences, Pawinskiego Street 5, 02-106 Warsaw, Poland.

Received: 1 June 2018 Accepted: 2 May 2019

Published online: 16 May 2019

\section{References}

1. Vahanian A, Baumgartner H, Bax J, Butchart E, Dion R, Filippatos G, Flachskampf F, Hall R, lung B, Kasprzak J, et al. Guidelines on the management of valvular heart disease: the task force on the management of Valvular heart disease of the European Society of Cardiology. Eur Heart J. 2007:2:230-68.

2. Albrecht GL, Devlieger PJ. The disability paradox: high quality of life against all odds. Soc Sci Med. 1999:(8):977-88.

3. Andresen EM, Vahle VJ, Lollar D. Proxy reliability: health-related quality of life (HRQoL) measures for people with disability. Qual Life Res. 2001;7:609-19.

4. Atherly A, Hebert PL, Maciejewski ML. An analysis of disenrollment from Medicare managed care plans by Medicare beneficiaries with diabetes. Med Care. 2005;(5):500-6.

5. Goldsmith IR, Lip GY, Patel RL. A prospective study of changes in the quality of life of patients following mitral valve repair and replacement. Eur J Cardiothorac Surg. 2001:5:949-55.

6. Hansen L, Winkel S, Kuhr J, Bader R, Bleese N, Riess FC. Factors influencing survival and postoperative quality of life after mitral valve reconstruction. Eur J Cardiothorac Surg. 2010;(3):635-44.

7. Hauptman PJ, Rector TS, Wentworth D, Kubo S. Quality of life in advanced heart failure: role of mitral regurgitation. Am Heart J. 2006;(1):213-8.

8. Suri RM, Antiel RM, Burkhart HM, Huebner M, Li Z, Eton DT, Topilsky T, Sarano ME, Schaff HV. Quality of life after early mitral valve repair using conventional and robotic approaches. Ann Thorac Surg. 2012;(3):761-9.

9. Ussia GP, Cammalleri V, Sarkar K, Scandura S, Imme S, Pistritto AM, Caggegi A, Chiaranda M, Mangiafico S, Barbanti M, et al. Quality of life following percutaneous mitral valve repair with the MitraClip system. Int J Cardiol. 2012;(2):194-200. 
10. Bayer-Topilsky T, Suri RM, Topilsky Y, Marmor YN, Trenerry MR, Antiel RM, Mahoney DW, Schaff HV, Enriquez-Sarano M. Psychoemotional and quality of life response to mitral operations in patients with mitral regurgitation: a prospective study. Ann Thorac Surg. 2015:(3):847-54.

11. Ferrari R, Vidotto G, Muzzolon C, Auriemma S, Salvador L. Neurocognitive deficit and quality of life after mitral valve repair. J Heart Valve Dis. 2014;1:72-8.

12. Lim DS, Reynolds MR, Feldman T, Kar S, Herrmann HC, Wang A, Whitlow PL, Gray WA, Grayburn P, Mack MJ, et al. Improved functional status and quality of life in prohibitive surgical risk patients with degenerative mitral regurgitation after transcatheter mitral valve repair. J Am Coll Cardiol. 2014;(2):182-92.

13. Mozenska O, Bil J, Segiet A, Kosior DA. Disorders of calcium and phosphate metabolism in patients with significant mitral regurgitation. Pol Arch Intern Med. 2018;4:222-7.

14. Berry EM, Gupta MM, Turner SJ, Burns RR. Variation in plasma calcium with induced changes in plasma specific gravity, total protein, and albumin. $\mathrm{Br}$ Med J. 1973;(5893):640-3.

15. Marshall RW, Hodgkinson A. Calculation of plasma ionised calcium from total calcium, proteins and pH: comparison with measured values. Clin Chim Acta. 1983;(2):305-10

16. Lancellotti P, Tribouilloy C, Hagendorff A, Moura L, Popescu BA, Agricola E, Monin JL, Pierard LA, Badano L, Zamorano JL, et al. European Association of Echocardiography recommendations for the assessment of valvular regurgitation. Part 1: aortic and pulmonary regurgitation (native valve disease). Eur J Echocardiogr. 2010;(3):223-44.

17. Lancellotti P, Moura L, Pierard LA, Agricola E, Popescu BA, Tribouilloy C, Hagendorff A, Monin JL, Badano L, Zamorano JL, et al. European Association of Echocardiography recommendations for the assessment of valvular regurgitation. Part 2: mitral and tricuspid regurgitation (native valve disease). Eur J Echocardiogr. 2010;(4):307-32.

18. Asadi-Lari M, Javadi HR, Melville M, Oldridge NB, Gray D. Adaptation of the MacNew quality of life questionnaire after myocardial infarction in an Iranian population. Health Qual Life Outcomes. 2003;1:23.

19. Dempster M, Donnelly M, O'Loughlin C. The validity of the MacNew quality of life in heart disease questionnaire. Health Qual Life Outcomes. 2004;2:6.

20. Vandereyt F, Dendale P, Vanhees L, Roosen J, Hofer S, Oldridge N. Psychometric properties of the Flemish version of the MacNew heart disease health-related quality of life questionnaire. Acta Cardiol. 2012;1:31-9.

21. Sillin $\mathrm{H}$, Rastad J, Ljunggren $\mathrm{O}$, Lundgren E. Disturbances of calcium homeostasis consistent with mild primary hyperparathyroidism in premenopausal women and associated morbidity. J Clin Endocrinol Metab. 2008;1:47-53.

22. Rostami Z, Hosseini MS, Lessan Pezeshki M, Heidari F, Einollahi B. Bone mineral metabolism and subsequent hospitalization with poor quality of life in dialysis patients. Nephrourol Mon. 2014;1:e14944.

23. Berry C, McMurray J. A review of quality-of-life evaluations in patients with congestive heart failure. Pharmacoeconomics. 1999;(3):247-71.

24. Dunderdale K, Thompson DR, Miles JN, Beer SF, Furze G. Quality-of-life measurement in chronic heart failure: do we take account of the patient perspective? Eur J Heart Fail. 2005;(4):572-82.

Ready to submit your research? Choose BMC and benefit from:

- fast, convenient online submission

- thorough peer review by experienced researchers in your field

- rapid publication on acceptance

- support for research data, including large and complex data types

- gold Open Access which fosters wider collaboration and increased citations

- maximum visibility for your research: over $100 \mathrm{M}$ website views per year

At $\mathrm{BMC}$, research is always in progress.

Learn more biomedcentral.com/submissions 